\title{
Cyanide intoxication by apricot kernels: A case report and literature review
}

\author{
Faruk Ekinci, ${ }^{1}$ Dincer Yildizdas, ${ }^{1}$ Alper Ates, ${ }^{2}$ Naime Gökay ${ }^{3}$ \\ ${ }^{1}$ Department of Pediatric Intensive and Critical Care, Faculty of Medicine, Çukurova University, Adana; \\ ${ }^{2}$ Department of Pediatrics, Adana Seyhan State Hospital, Adana; ${ }^{3}$ Department of Pediatric Intensive and \\ Critical Care, Adana Seyhan State Hospital, Adana, Turkey
}

\begin{abstract}
Acute cyanide intoxication is a serious healthcare problem due to its potentially life threatening and fatal toxic effects. Ingestion of cyanide containing foods is an important source of cyanide poisoning and apricot kernels contain significant amounts of such cyanogenic compounds. Herein we report a previously healthy 4year-old boy admitted to our emergency department with complaints of vomiting and sudden onset of unconsciousness after ingestion of apricot kernels. He was diagnosed as acute cyanide poisoning and treated with a specific antidote; hydroxocobalamin. Our report concludes with previous cases of cyanide poisoning after ingestion of apricot kernels and a quick look at sources, manifestations and treatment of acute cyanide poisoning.
\end{abstract}

Correspondence: Faruk Ekinci, Department of Pediatric Intensive and Critical Care, Faculty of Medicine, Çukurova University, Adana, Turkey.

Tel.: +90.322.3386060 - Fax: +90.322 .3386572$

E-mail: farukekinci83@gmail.com

Key words: Apricot kernels; Cyanide; Hydroxocobalamin.

Contributions: FE, corresponding author, wrote the manuscript, literature review; DY, review and check for the final version; AA, data collection, editing the manuscript; NG, literature review, data collection. All of the authors approved the final version of the manuscript.

Conflict of interest: the authors declare no potential conflict of interest.

Funding: none.

Informed consent: written informed consent was obtained from a legally authorized representative (father) for anonymized patient information to be published in this article.

Received for publication: 29 April 2019.

Revision received: 20 June 2019.

Accepted for publication: 1 July 2019.

This work is licensed under a Creative Commons Attribution 4.0 License (by-nc 4.0)

(C) Copyright: the Author(s), 2019

Licensee PAGEPress, Italy

Emergency Care Journal 2019; 15:8256

doi:10.4081/ecj.2019.8256

\section{Introduction}

Acute cyanide intoxication is one of the most potent and dangerous poisoning and still a public healthcare problem affecting individuals all around the world. Although it is known to be a chemical used in industrial products, it presents as cyanogenic glycosides known as amygdaline in several plants and fruits including seeds of bitter almonds, peach, cherry, pear, plum, apple, apricot, lima beans and cassava plants. ${ }^{1}$ Smoke inhalation in fire is known to be the most common reason of acute cyanide poisoning in both children and adults, but oral route of poisoning by such amygdaline containing foods is reported in an increasing manner in children living in tropical countries where these cyanogenic foods are important part of the diet. Apricot kernels are the leading foods most likely to cause cyanide toxicity because of containing high amygdaline concentration and their ability to easily release their hydrogen cyanide content. ${ }^{2}$ In this article, we present a 4 -year-old pediatric case with acute cyanide poisoning after ingestion of apricot kernels, successfully treated with intravenous administration of hydroxocobalamin. Our report concludes with a literature review of cyanide poisoning and previous cases with this significant and potentially fatal poisoning after ingestion of apricot kernels.

\section{Case Report}

A previously healthy 4-year-old, $16 \mathrm{~kg}$ boy admitted to our pediatric emergency department with nausea, vomiting and sudden onset of unconsciousness. His parents reported that he had eaten approximately 15-20 apricot kernels one hour before admission. Within 20 minutes he started vomiting and 30 minutes after ingestion, he became totally unconscious and did not awake until arrival to the hospital.

On arrival at the emergency department, approximately one hour after ingestion, the patient was confused with intervals of agitation and pediatric Glasgow coma scale score was 8 . His vital signs were: blood pressure $101 / 45 \mathrm{~mm} \mathrm{Hg}$, pulse rate 156 beats $/ \mathrm{min}$, respiratory rate 28 breaths $/ \mathrm{min}$, temperature $36.8^{\circ} \mathrm{C}$ and $\mathrm{SpO}_{2}$ on room air was $99 \%$. The patient was comatose, unresponsive to painful stimuli, his respirations were deep and irregular. Cardiovascular and lung examination were normal and there were no signs of shock in the initial physical examination. On neurological examination increased deep tendon reflexes and bilateral extensor plantar response were determined. An electrocardiography was performed and sinus tachycardia was detected. Arterial blood gas analysis revealed metabolic acidosis and lactic acidosis (pH 7.21, $\mathrm{pO}_{2} 75 \mathrm{~mm} \mathrm{Hg}, \mathrm{pCO}_{2} 24 \mathrm{~mm} \mathrm{Hg}, \mathrm{HCO}_{3} 13 \mathrm{mmol} / \mathrm{L}$, base excess $-13 \mathrm{mmol} / \mathrm{L}$ and lactate $8.1 \mathrm{mmol} / \mathrm{L})$. Anion gap was increased; $22 \mathrm{meq} / \mathrm{L}$. The venous blood was bright red in colour 
and $\mathrm{pO}_{2}$ in venous blood was $58 \mathrm{~mm} \mathrm{Hg}$. Blood glucose was 149 $\mathrm{mg} / \mathrm{dL}$ and other laboratory tests including complete blood count, blood chemistry, coagulation parameters, urine analysis, urine toxicology, heavy metal screening and imaging tests of chest X-ray and cerebral computed tomography were all normal. We could not measure blood cyanide level due to lack of laboratory. Based on the clinical and laboratory findings and a positive history of eating apricot kernels, he was diagnosed with acute cyanide poisoning due to oral ingestion of amygdalin containing food. After clinical consultation with the clinical toxicology unit, gastric lavage was performed and $1 \mathrm{~g} / \mathrm{kg}$ activated charcoal was administered by nasogastric tube. Supplementary oxygen with a flow rate of 15 $\mathrm{L} / \mathrm{min}$ was administered via oxygen mask with reservoir bag. The patient was transferred to pediatric intensive care unit for further evaluation and treatment. One vial containing $5 \mathrm{~g}$ of hydroxocobalamin (Cyanokit, Merck Sante, Semoy, France) was reconstituted with $200 \mathrm{~mL}$ of $0.9 \%$ saline solution as the manufacturer recommends and pediatric dosage of $70 \mathrm{~mL} / \mathrm{kg}$ was administered as intravenous infusion over 30 minutes (the start of administration was approximately 4 hours after ingestion). The arterial blood gas was totally normal 4 hours after hydroxocobalamin treatment but neurologic symptoms including confusion and lethargy were still on and a second dose of hydroxocobalamin was administered with the same dosage four hours later. This second administration made a rapid and exact clinical improvement. A slight and transient chromaturia was observed and no other serious adverse reactions including allergic reactions, increase in blood pressure, erythema and infusion site reactions occurred. The patient was discharged from hospital after 3 days with full clinical recovery.

\section{Discussion}

Cyanide is one the most potent, deadly and rapidly acting of all known poisons and cyanide poisoning is still a serious healthcare problem affecting individuals all around the world. ${ }^{3}$ It is commonly used in many industrial products such as household or workplace substances and is found in common materials such as fabrics containing nylon, silk, wool or many plastics such as melamine, polyurethane and polyacrylonitrile. ${ }^{4}$ In light of this fact, it is not surprising that inhalation of fire smoke is the most common source of cyanide poisoning. This entity is due to inhalation of cyanide and cyanogenic compounds after combustion of these widely used products. There are several reports indicating the elevated blood cyanide levels in the victims exposed to fire smoke. ${ }^{5}$ Cyanide is thought to be a contributor to death in conjunction with the presence of elevated carbon monoxide levels and hypoxemia in these victims. There are other several routes of cyanide intoxication including; accidental or suicidal oral ingestion of these household and workplace substances (especially acetonitrile which is a solvent used in cosmetics as false fingernail removers, containing high concentrations of inorganic cyanide), iatrogenically by intravenous infusion of nitroprusside (a widely used anti-hypertensive agent in hypertensive crisis, known to be converted to free cyanide in blood-contains $44 \%$ cyanide in molar weight) and eating cyanogenic foods. ${ }^{6,7}$

Cyanide poisoning can be observed after ingestion of plants, herbs and foods containing cyanogenic glycosides. Cyanogenic glycosides are chemical compounds contained in foods that release hydrogen cyanide when chewed or digested. There are approximately 25 known cyanogenic glycosides and these are found naturally in at least 2600 types of plants, seeds and foods. ${ }^{8}$ Although cyanide poisoning by ingestion of these foods is very rare in developed countries, it is reported more frequently in tropical countries where these foods are consumed much more as a part of routine diet. One of the best examples is cassava plant (also known as tapioca) which is hydrolyzed to glucose, hydrogen cyanide and acetone by intestinal $\mathrm{b}$ glucosidase. The high carbonhydrate and protein content of this plant makes it an important part of the diet especially in African region, South America and Southeast Asia. However, its use as a part of routine diet is heavily handicapped by its high content of cyanogenic glycosides such as linamarin, lotaustralin and amygdalin. ${ }^{9}$ Several cases of cyanide poisoning after ingestion of cassava plants have been reported both in children and adults to date. ${ }^{10,11}$

The other important source of cyanogenic compounds is apricot kernels. It contains amygdaline, a cyanogenic glycoside, hydrolyzed to hydrogen cyanide, glucose, benzaldehyde and emulsin in the alkaline environment of the small intestines by $b$ glucosidase. ${ }^{12}$ One of the end products; emulsin, acts like b glucosidase, thus catalyzes the hydrolysis of amygdalin which contributes to cyanide intoxication after ingestion. Another important issue is that; chewing rather than swallowing completely without chewing increases the probability of poisoning because the act of chewing leads to hydrolysis of the substances, causing cyanide to be released. There are 2 types of apricot kernels: bitter and sweet. Bitter apricot kernels are known to contain higher amounts of amygdaline; making them extremely unsafe for consumption. ${ }^{13}$ The hydrogen cyanide content in apricot kernels varies widely in a range of $122-4000 \mathrm{mg} / \mathrm{kg}$, with a mean content of $2920 \mathrm{mg} / \mathrm{kg}$ or approximately $0.5 \mathrm{mg}$ cyanide/kernel. ${ }^{14}$ Abraham et al. reported a cyanide content of $3250 \mathrm{mg} / \mathrm{kg}$ in bitter apricot kernels which is higher than other cyanogenic foods. ${ }^{15}$ Rubino and Davidoff reported cyanide poisoning after ingestion of 20-40 apricot seeds in a 49year-old woman in $1979 .{ }^{16}$ This case is known to be the first case report in the literature. In this report, the patient became symptomatic with headache, weakness, nausea, vomiting and disorientation within half an hour after ingestion and was treated successfully with amyl nitrite, sodium nitrite and sodium thiosulfate. The report ends with a warning about ingestion and marketing of such cyanogenic foods to prevent this type of needless poisonings, but despite this warning, apricot kernels were continued to be marketed for its presumed healthful effects. About 20 years later, Suchard et al. published the second case report in 1998.12 The patient was a 41-year-old woman presented with nearly the same symptoms after ingestion of 30 apricot kernels. The other published case reports ${ }^{12,16-30}$ from various parts of the world including our country are listed in Appendix Table 1.

Cyanide causes intracellular hypoxia by inactivating mitochondrial cytochrome oxidase which results in impairment of oxidative phosphorylation and a switch to anaerobic metabolism, lactic acidosis and energy depletion in whole body. ${ }^{31}$ The symptoms and clinical manifestations of cyanide poisoning are non-specific and often related to oxygen and energy deprivation, especially in heart and brain tissue (Appendix Table 2). The early manifestations are anxiety, headache, dizziness, confusion, tachypnea, tachycardia and vomiting. As hypoxia progresses more serious symptoms of central nervous system and heart occurs; with decreased level of consciousness, seizures, apnea, coma, arrhythmias and signs of cardiovascular collapse. Appendix Table 1 shows that most of the patients admitted to hospital with complaints of headache, weakness, vomiting and decreased level of consciousness from agitation to coma. One of the 17 patients died, and 2 patients developed neurological sequelae with findings of hypoxemia in cranial imaging. The time to onset of symptoms is affected 
by the form of cyanide, the route of exposure and the content of cyanide in the toxic substance. Inhalation poisonings can be symptomatic within less than 1 minute and can be lethal within a few minutes. The time to onset of symptoms after ingestion of cyanogenic foods varies due to the amount of ingestion and cyanide content of the food. Ruangkanchanasetr et al. reported two pediatric patients with cyanide poisoning after eating boiled cassava who became symptomatic about 9 hours after ingestion. ${ }^{11}$ Akyildiz et al. reported cyanide poisoning after apricot seed ingestion in 13 children and mean time to onset of symptoms was 60 minutes (range 20 mins to $3 \mathrm{hrs}$ ). ${ }^{32}$ One of the most extensive data on cyanide poisoning after apricot kernel ingestion was reported from Gaza by Lasch and El Shawa, establishing time to onset of symptoms was 30 mins to 2 hours in 24 patients. ${ }^{33}$ In Appendix Table 1 , the time to onset of symptoms was between 15 minutes and 2 hours. Our patient in the case report became symptomatic within 20 mins after ingestion. The initial symptom was vomiting with a rapid deterioration in general appearance and he was totally unconscious 30 mins after ingestion.

The laboratory evaluations in cyanide poisoning is nonspecific and that makes the diagnosis difficult especially if there is not a positive history of smoke inhalation, occupational exposure or eating cyanogenic foods. The shift to glycolysis through anaerobic metabolism induces production of lactate as an end-product which results in a high anion-gap metabolic acidosis. ${ }^{34}$ In $67 \%$ of patients with cyanide poisoning, there is acute onset of metabolic acidosis. ${ }^{35}$ Lactic acidosis was shown to be highly sensitive ad moderately specific for cyanide poisoning in a series of adults exposed to cyanide. In this study, a plasma lactate level of $\geq 72 \mathrm{mg} / \mathrm{dL}(\geq 8$ $\mathrm{mmol} / \mathrm{L}$ ) was found to be $94 \%$ sensitive and $70 \%$ specific for a blood cyanide level of $\geq 1 \mathrm{mg} / \mathrm{L} .{ }^{36}$ A bitter almond-like smell on breath, a positive history of eating apricot kernels, sudden clinical deterioration and onset of high anion-gap metabolic acidosis with lactic acidosis should seriously be diagnosed with acute cyanide poisoning after excluding other reasons of high anion-gap metabolic acidosis. There are some other supportive findings that can be present in this poisoning, like elevated oxygen content in venous blood. This is related to inability of cells to extract oxygen from the blood because cyanide causes the cessation of aerobic cellular respiration. In the victims of cyanide poisoning, the color of the venous blood is bright-red like arterial blood, and cyanosis is often not present in spontaneously breathing or mechanically ventilated patients. This phenomenon is sometimes referred to as arterialization of venous blood, which imply the reduced arteriovenous oxygen saturation difference $(<10 \mathrm{~mm} \mathrm{Hg}) .{ }^{37}$ Another important laboratory finding is the elevated cyanide concentrations in whole blood, if feasible. Serum concentrations of cyanide greater than 0.5 $\mathrm{mg} / \mathrm{L}$ are associated with acute cyanide poisoning and $>3 \mathrm{mg} / \mathrm{L}$ is presumed to be lethal. ${ }^{38}$ Although it is a valuable parameter in defining the final diagnosis, the need for the emergency treatment of this possibly fatal poisoning and relatively long times to obtain laboratory measurements makes it unhelpful in initial diagnosis. Furthermore, serum cyanide concentrations do not correlate well with the severity of the symptoms. As a result, to decide whether to administer specific antidotal therapy or not is based on a high suspicion from history of the patient and supportive laboratory findings, especially high anion-gap metabolic acidosis and lactic acidosis.

The management of acute cyanide poisoning after oral ingestion is listed in Appendix Table 3. The first step in management is the initial supportive care; involves the basic life support with stabilization of vital signs (ABCs) and establishing an intravenous access as soon as possible. Gastric decontamination and adminis- tration of activated charcoal should be performed in the first 1 to 4 hours. ${ }^{38}$ For patients who vomited, care must be taken by healthcare providers to avoid secondary contamination. Personal protective materials must be used during decontamination. The activated charcoal is most effective if performed in the first hour after ingestion because of the high potency of cyanide and rapid onset of symptoms. ${ }^{34}$ One of the most important steps in management is administration of $100 \%$ oxygen by non-rebreather mask, high flow systems or endotracheal tube because a critical deficiency in oxygen utilization is the main pathology in acute cyanide intoxication. ${ }^{39}$ Oxygen is shown to enhance the effectiveness of antidotal therapy in many animal studies and in humans by competing with cyanide for cytochrome oxidase binding sites, reactivating mitochondrial enzymes and activating other oxidative systems. ${ }^{39,40}$

After these initial supportive cares, a specific antidote must be administered as soon as possible, as the mainstream of the therapy, especially in critical patients. The answer of which antidote is the most effective? is still controversial. The cyanide antidote kit, which consists of three drugs given together: amyl nitrite-sodium nitrite-sodium thiosulfate, is known to be the first antidote but it is no longer available. ${ }^{39}$ The nitrite parts of the drug induce methemoglobinemia to bind free cyanide. Cyanide tends to bind methemoglobin rather than cytochrome oxidase so that the depression of the mitochondria is decreased. Physiological levels of cyanide are metabolized to thiocyanate by the enzyme rhodanese, which requires thiosulphate as a substrate. The body's reserve of thiosulphate is limited, suggesting supplementation might be beneficial in cyanide poisoning. Sodium thiosulfate serves as a sulfur donor in rhodanese-catalyzed formation of thiocyanate (much less toxic than cyanide). Monitoring methemoglobin levels is indicated and should not exceed $20 \%$ because this may exacerbate the hypoxemia in patients with poor cardiopulmonary status, especially in fire smoke victims and in pregnant women. An alternative kit containing sodium nitrite and sodium thiosulfate is available.

Sodium thiosulfate can be used alone or in combination with hydroxocobalamin. When used alone, it is effective but antidotal effect is slower than hydroxocobalamin. Hydroxocobalamin, approved in 2006 by Food and Drug Administration, binds to cyanide to form nontoxic cyanocobalamin. Because it does not induce methemoglobinemia and it has fewer side effects, it is being used widely all around the world as the first choice of therapy, if available. It is proved to be safer than cyanide antidote kit in exposure to carbon monoxide in fire smoke victims and in pregnant women because it does not compromise the oxygen-carrying capacity of hemoglobin. ${ }^{41}$ Another antidote; dicobalt edetate (Kelocyanor) has been shown to be effective in acute cyanide poisoning but it has serious potential adverse effects such as hypertension, nausea, vomiting, urticaria, laryngeal edema, anaphylactic shock, hypotension and arrythmias. ${ }^{40}$ So, its use in cyanide poisoning is limited and efficacy and safety of this drug in pediatric use are lacking.

\section{Conclusions}

In conclusion, acute cyanide intoxication due to cyanogenic foods is still a remarkable problem in certain regions of the world. Apricot kernels are one of these foods being consumed widely all around the world including our country due to its benefits on human health. Clinicians should be alert about the ingestion of these foods and consider acute cyanide poisoning in differential 
diagnosis of the patients presenting with sudden onset of neurologic depression and metabolic acidosis with severe lactic acidosis. After reviewing previous cases, we also wanted to highlight the fact that appropriate supportive care and antidotal treatment in the first hours is critical and would be life-saving.

\section{References}

1. Geller RJ, Barthold C, Saiers JA, Hall AH. Pediatric cyanide poisoning: causes, manifestations, management, and unmet needs. Pediatrics 2006;118:2146-58.

2. Barceloux DG. Cyanogenic foods (cassava, fruit kernels, and cycad seeds). Dis Mon 2009;55:336-52.

3. World Health Organization. Hydrogen cyanide and cyanides: human health aspects. Concise International Chemical Assessment Document 61. Geneva, Switzerland: World Health Organization; 2004.

4. Betol E, Mari F, Orzalesi G, Volpato I. Combustion products from various kinds of fires: toxicological hazards from smoke exposure. Forensic Sci Int 1983;22:111-6.

5. Baud FJ, Barriot P, Toffis V, et al. Elevated blood cyanide concentrations in victims of smoke inhalation. N Engl J Med 1991;325:1761-6.

6. Geller RJ, Ekins BR, Iknoian RC. Cyanide toxicity from acetonitrile-containing false nail remover. Am J Emerg Med 1991;9:268-70.

7. Pershau RA, Modell JH, Bright RW, Shirley PD. Suspected sodium nitroprusside-induced cyanide intoxication. Anesth Analg 1977;56:533-53.

8. Haque MR, Bradbury JH. Total cyanide determination of plants and foods using the picrate and acid hydrolysis methods. Food Chem 2002;77:107-14.

9. Lykkesfeldt J, Moller BL. Cyanogenic glycosides in cassava, Manihot esculenta Crantz. Acta Chem Scand 1994;48:178-80.

10. Cheok SS. Acute cassava poisoning in children in Sarawak. Trop Doct 1978;8:99-101.

11. Ruangkanchanasetr S, Wananukul V, Suwanjutha S. Cyanide poisoning, 2 cases report and treatment review. J Med Assoc Thai 1999;82:162-7.

12. Suchard JR, Wallace KL, Gerkin RD. Acute cyanide toxicity caused by apricot kernel ingestion. Ann Emerg Med 1998;32:742-4.

13. Bolarinwa IF, Orfila C, Morgan MRA. Determination of amygdalin in apple seeds, fresh apples and processed apple juices. Food Chem 2015;170:437-42.

14. Holzbecher MD, Moss MA, Ellenberger HA. The cyanide content of laetrile preparations, apricot, peach and apple seeds. Clin Toxicol 1984;22:341-7.

15. Abraham K, Buhrke T, Lampen A. Bioavailability of cyanide after consumption of a single meal of foods containing high levels of cyanogenic glycosides: a crossover study in humans. Arch Toxicol 2016;90:559-74.

16. Rubino MJ, Davidoff F. Cyanide poisoning from apricot seeds. JAMA 1979;241:359.

17. Cigolini D, Ricci G, Zannoni M, et al. Hydroxocobalamin treatment of acute cyanide poisoning from apricot kernels. Emerg Med J 2011;28:804-5.

18. Sauer H, Wollny C, Oster I, et al. Severe cyanide poisoning from an alternative medicine treatment with amygdalin and apricot kernels in a 4-year-old child. Wien Med Wochenschr 2015;165:185-8.

19. Vlad IA, Armstrong J, Bertilone C, Matisons M. Apricot kernels: a rare case of cyanide toxicity. Emerg Med Australas 2015;27:491-2.

20. Ak1l M, Kaya A, Ustyol L, et al. Acute cyanide intoxication due to apricot seed ingestion. J Emerg Med 2013;44:285-6.

21. Sahin S. Cyanide poisoning in a children caused by apricot seeds. J Health Med Informat 2011;2:106.

22. Unal O, Ozen O, Caksen H. Acute cyanide intoxication related to apricot seed: The findings of cranial magnetic resonance imaging. J Neurol Sci 2016;33:171-6.

23. Ozcan M, Ozcan FB, Yasartekin Y, et al. Acute cyanide poisoning caused by apricot kernel. Cukurova Med J 2017;42:600-1.

24. Dogan M, Y1lmaz C, Kaya A, et al. Cyanide intoxication with encephalitis clinic: a case report. Eas J Med 2006;11:22-5.

25. Sen TA, Koken R, Demir T, et al. Acute cyanide intoxication after apricot kernel ingestion. Turk J Pediatr Dis 2009;3:38-41.

26. Kaya A, Okur M, Ustyol L, et al. Acute cyanide poisoning after eating apricot pits: a case report. Turk Arch Ped 2012;47:1412.

27. Saz EU, Tekguc H, Kalkan S, et al. Successful treatment of severe cyanide poisoning due to apricot kernels. J Turk Soc Intensive Care 2009;7:166-9.

28. Tatli M, Eyupoglu G, Hocagil H. Acute cyanide poisoning due to apricot kernel ingestion. J Acute Dis 2017;6:87-8.

29. Tanriverdi MH, Uysal C, Bucaktepe PG, et al. Cyanide toxicity caused by apricot kernel: A case presentation. Euroas J Fam Med 2014;3:119-22.

30. Ozkan G, Karc1 I, Ates AG, et al. Acute cyanide poisoning that occurs with apricot kernel eating in two sisters. Smyrna Med J 2013;2:47-9.

31. Dart RC, Bogdan GM. Acute cyanide poisoning: causes, consequences, recognition and management. Frontline First Responder 2004;2:19-22.

32. Akyildiz BN, Kurtoğlu S, Kondolot M, Tunç A. Cyanide poisoning caused by ingestion of apricot seeds. Ann Trop Paediatr 2010;30:39-43.

33. Lasch EE, El Shawa R. Multiple cases of cyanide poisoning by apricot kernels in children from Gaza. Pediatrics 1981;68:5-7.

34. Shepherd G, Velez L. Role of hydroxocobalamin in acute cyanide poisoning. Ann Pharmacother 2008;42:661-9.

35. Agency for Toxic Substances and Disease Registry. Toxicological Profile for Cyanide (update). (ATSDR/TP92/09). Atlanta, GA: US Department of Health and Human Services, Public Health Service; 2006. pp 1-341.

36. Baud FJ, Borron SW, Mégarbane B, et al. Value of lactic acidosis in the assessment of the severity of acute cyanide poisoning. Crit Care Med 2002;30:2044-50.

37. Nelson L. Acute cyanide toxicity: mechanisms and manifestations. J Emerg Nurs 2006;32:S8-11.

38. Borron SW. Recognition and treatment of acute cyanide poisoning. J Emerg Nurs 2006;32:S12-8.

39. Barillo DJ. Diagnosis and treatment of cyanide toxicity. J Burn Care Res 2009;30:148-52.

40. Megarbane B, Delahaye A, Goldgran-Toledano D, Baud FJ. Antidotal treatment of cyanide poisoing. J Chin Med Assoc 2003;66:193-203.

41. Hall AH, Dart R, Bogdan G. Sodium thiosulfate or hydroxocobalamin for the empiric treatment of cyanide poisoning? Ann Emerg Med 2007;49:806-13. 